\title{
FY-09 Summary Report to the Office of Petroleum Reserves on the Western Energy Corridor Initiative Activities and Accomplishments
}

January 2010

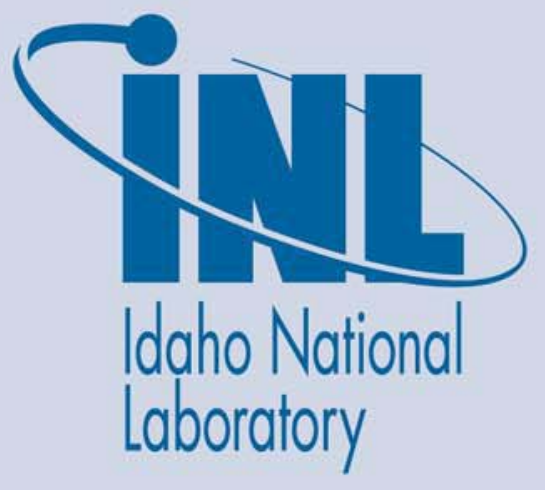

The INL is a U.S. Department of Energy National Laboratory operated by Battelle Energy Alliance 
INL/EXT-10-17732

\title{
FY-09 Summary Report to the Office of Petroleum Reserves on the Western Energy Corridor Initiative Activities and Accomplishments
}

January 2010

\author{
Idaho National Laboratory \\ Idaho Falls, Idaho 83415
}

http://www.inl.gov

Prepared for the

U.S. Department of Energy

Assistant Secretary for Fossil Energy

Under DOE Idaho Operations Office

Contract DE-AC07-05ID14517 


\section{DISCLAIMER}

This information was prepared as an account of work sponsored by an agency of the U.S. Government. Neither the U.S. Government nor any agency thereof, nor any of their employees, makes any warranty, expressed or implied, or assumes any legal liability or responsibility for the accuracy, completeness, or usefulness, of any information, apparatus, product, or process disclosed, or represents that its use would not infringe privately owned rights. References herein to any specific commercial product, process, or service by trade name, trade mark, manufacturer, or otherwise, does not necessarily constitute or imply its endorsement, recommendation, or favoring by the U.S. Government or any agency thereof. The views and opinions of authors expressed herein do not necessarily state or reflect those of the U.S. Government or any agency thereof. 



\section{OVERVIEW}

To meet its programmatic obligations under the Energy Policy Act of 2005, the Office of Naval Petroleum and Shale Oil Reserves (NPSOR) has initiated the Western Energy Corridor Initiative (WECI). The WECI will implement the Unconventional Strategic Fuels Task Force recommendations for accelerating and promoting the development of domestic unconventional fuels to help meet the nations' energy needs. The mission of the WECI is to bolster America's future fuel security by facilitating socially and environmentally responsible development of unconventional fuels resources in the Western Energy Corridor, using sound engineering principles and science-based methods to define and assess benefits, impacts, uncertainties, and mitigation options and to resolve impediments. The Task Force proposed a three-year program in its commercialization plan.

The work described herein represents work performed by Idaho National Laboratory (INL) in support of the DOE's WECI. This effort represents an interim phase of work, designed to initiate only select portions of the initiative, limited by available funding resources within NPOSR. Specifically, the work presented here addresses what was accomplished in FY-09 with the remaining carryover $(\sim 420 \mathrm{~K})$ from NPOSR FY-08 funds. It was the intent of the NPOSR program to seek additional funding for full implementation of the full scope of work; however, the funding did not materialize, and the original tasks were reduced in scope, terminated, or eliminated (as noted below). An effort is ongoing to obtain funding to continue the tasks initiated under this project.

The INL deliverables will be integrated into an overall NPOSR WECI work plan that will include scope performed by other entities, including Intek, Inc., and Los Alamos National Laboratory (LANL). The tasks described below will feed directly into the larger work plan. The study will focus on the integrated development of multiple energy resources in a carbon-neutral and environmentally acceptable manner. Emphasis will be placed on analyses of the interrelationships of various energy-resource development plans and the infrastructure, employment, training, fiscal, and economic demands placed on the region as a result of various development scenarios. The interactions at build-out during the design, permitting, and construction of individual and multiple energy developments are not fully considered at the local, state, regional, or national levels. The net impacts to the Western Energy Corridor cannot be understood and the design optimized under the current approach. A regional development plan is needed to model cumulative impacts, determine the carrying capacity of the basin, and provide valuable technically based information to both skeptics and advocates.

The INL scope of work for FY-09 involved six tasks:

1. Evaluation of the ASPEN Code as a dynamic systems model for application and use under the WECI and communications with Alberta Oil Sands Research Institutions as an "analog" resource development in the Western Energy Corridor

2. Application of the Aspen Plus computer model to several oil shale processes to consider energy balances and inputs and outputs (e.g. water consumption, $\mathrm{CO}_{2}$ production, etc.)

3. Development of a regulatory roadmap for oil shale developments

4. Defining of the physiographic extent of the natural resource reserves that comprise the Western Energy Corridor

5. A review of the Unconventional Fuels Task Force Report to Congress for ideas, concepts and recommendations that crosscutting plans

6. Program development with stakeholders, including industry, academics, state and federal agencies, and non government organizations. This task also includes project management, strategic development and reporting. 


\section{TASK 1 Dynamic Systems Modeling and Alberta Analog}

\section{Task 1.1 ALCES analysis tool review and analysis}

ALCES (A Landscape Cumulative Effects Simulator) is a system dynamics model that is able to simultaneously consider the cumulative effects among a wide variety of land uses ranging from energy development, recreation, agriculture, forestry, and human development. ALCES was developed in Alberta for the purpose of integrated resource management. It is a user-friendly landscape simulator that enables resource managers, industry, society, and the scientific community to explore and quantify dynamic landscapes affected by human land-use practices and by various natural disturbances. In this task, the INL evaluated the ALCES code for suitability as a potential tool to address development of unconventional fossil energy resources within the Western Energy Corridor.

\section{Task 1.2 Problem development, analysis of solutions, collaborations with Canadians}

The development of Canadian oil sands is, in many ways, a prototype for energy development in the WESTERN ENERGY CORRIDOR (as recognized in the Energy Policy Act 2005). This subtask has strengthened ties to Canadian researchers so that long-term relationships are being built to enhance the transfer of knowledge and experience obtained in developing unconventional resources in Canada to the WECI. Under subtask 1.2, the INL and University of Calgary scientists prepared a white paper describing an approach for energy development of Alberta oil sands to be optimized with the design and construction of power and heat plants. This white paper was delivered to NPOSR with documents prepared for the project mid-year review in March, 2009. The INL and the University of Calgary continue to seek funding to support this research.

\section{TASK 2.0 Aspen modeling of representative oil shale processes}

Understanding the $\mathrm{CO}_{2}$ and water footprint of oil shale development under various process scenarios requires a rigorous understanding of material and energy balances. Process parameters such as stream composition, temperature, and pressure can be input, and Aspen will calculate outlet composition and conditions for a given unit operation. Unit operations can be combined to represent very complex chemical processes.

\section{Task 2.1 Select and define the shale oil processes for evaluation}

Numerous in-situ and ex-situ processes have been proposed for recovery of oil from shale. A literature study was performed to identify the most promising technologies, and two processes were selected, one in-situ and one ex-situ. The deliverable from this task is a written summary of the literature survey and a process flow diagram, which are provided in Section of this report.

\subsection{Develop steady-state Aspen+model for selected processes (terminated prior to start due to lack of funding)}

A steady-state process model was to be developed for each selected process, and enough detail included in the model to assess the energy balance and estimate water consumption.

\subsection{Evaluate the economic feasibility of each selected process (terminated prior to start due to lack of funding)}

Results from Task 2.2 were to be used to estimate capital and operating costs for each process configuration.

\section{TASK 3.0 Regulatory Road Map (terminated prior to start due to lack of funding)}

\subsection{Interview oil companies and permitting agencies}

Permitting and approval of new oil shale developments were identified as potential stumbling blocks to the commercialization of strategic unconventional fuels by the task force. The long-term goal of this task is to create a permitting process for the various unconventional fuels processes that will enable 
applications to be approved in a logical order that maximizes the realization of program objectives, but minimizes associated risks and creates flexibility in future decisions. As a first step towards developing a regulatory roadmap, a report was to be generated describing the overall permitting process for oil shale development.

\section{TASK 4.0 Resource characterization and modeling (terminated mid year due to lack of funding)}

\subsection{Prepare maps and figures as needed to define resource distribution and prepare GIS layers as} required

The area of the WESTERN ENERGY CORRIDOR is characterized by an overlapping distribution of conventional and unconventional fossil fuel resources. The close proximity of the resources creates unique problems for the environment, infrastructure, and local communities. Mapping and definition of the distribution of resources within the WESTERN ENERGY CORRIDOR is required to develop reports and support documentation for design and planning. Under this task, a partial analysis of maps and estimates prepared by others was conducted and was transmitted to DOE in March of 2009 with the midyear documentation.

\section{TASK 5.0 Review Task Force Crosscutting Plans (terminated prior to start due to funding)}

\subsection{Review crosscutting plans to identify issues and proposed solutions applicable to WECI}

The 2007 Task Force on Strategic Unconventional Fuels Report to Congress presents numerous plans for accelerating the development of unconventional fuels in the United States. This task was to review the crosscutting plans for applicability and merit for the WECI.

\section{TASK 6.0 Communications (terminated mid year due to lack of funding)}

In order to effectively develop science and technology to understand and mitigate the environmental and social issues associated with unconventional fuels development, a thorough understanding of the issues of interest and their relative importance to a wide variety of people and groups is required. Various groups have a vested interest regarding which issues are addressed and how solutions are developed and implemented. State and federal regulators, development and extraction companies, land managers, local governments, and non-governmental organizations (NGOs) all have an interest in understanding issues associated with development of the western unconventional fuels resources. These stakeholders all have recourse, via legal or political means, to influence whether and how a resource is developed and the requirements placed on any operation.

The results of the Task 6, Communication, were transmitted to NPOSR in March 2010 with the mid-year review materials. 


\section{CONTENTS}

OVERVIEW

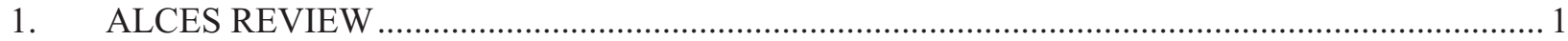

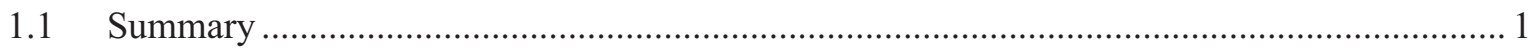

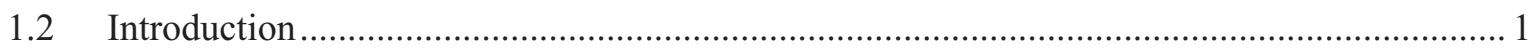

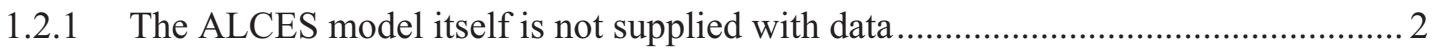

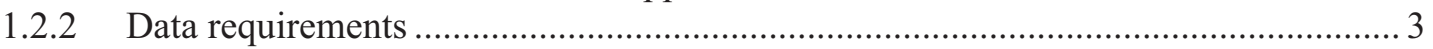

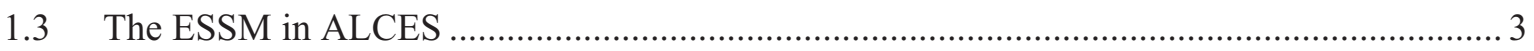

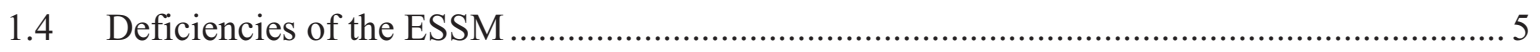

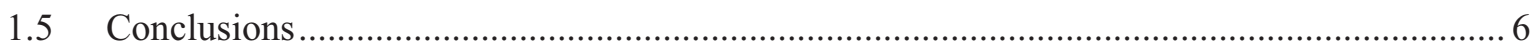

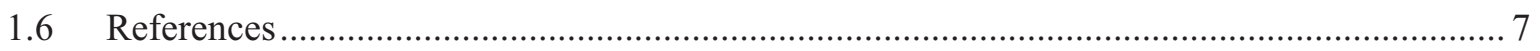

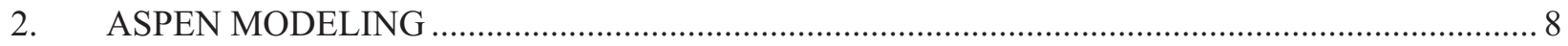

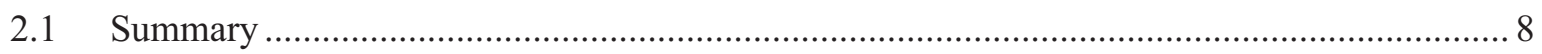

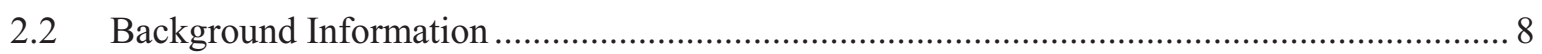

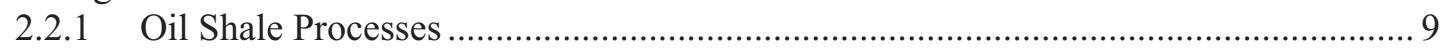

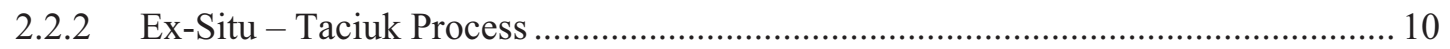

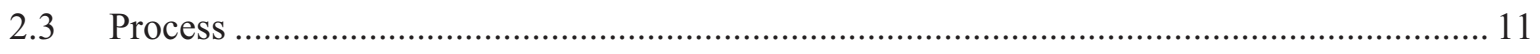

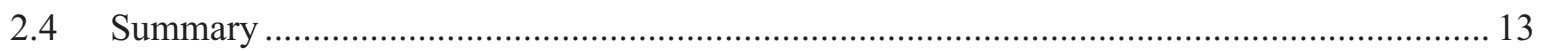

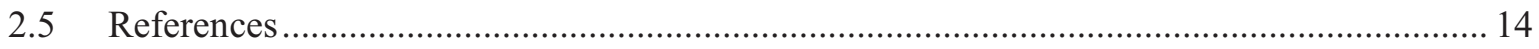

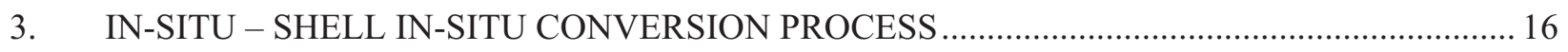

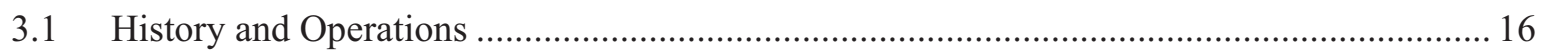

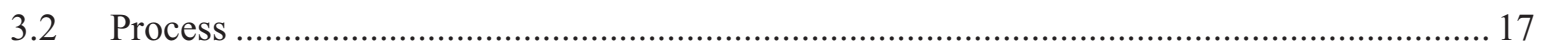

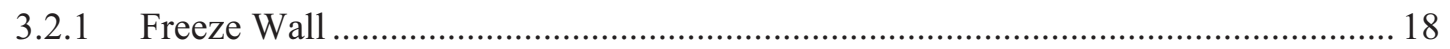

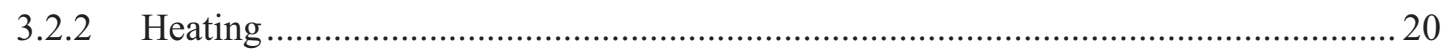

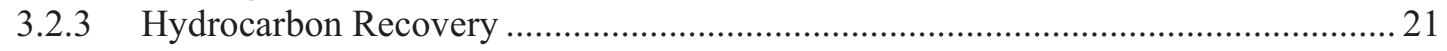

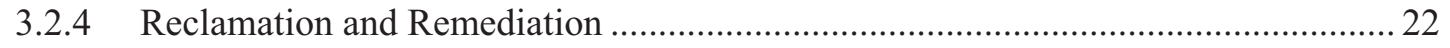

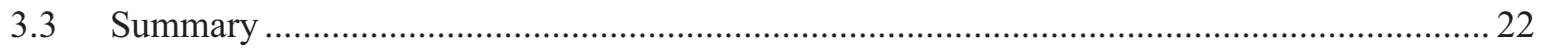

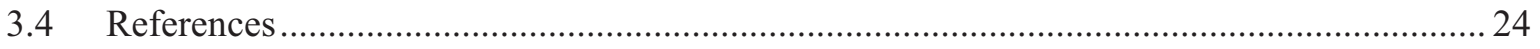

FIGURES

Figure 1. ATP System flow diagram processor (Source: DOI, 2007) ..................................................... 12

Figure 2. Pictorial representation of ATP Processor (Source: Taciuk, 2008)........................................ 13

Figure 3. Flow schematic for the ATP and related processes to support oil shale retorting (from

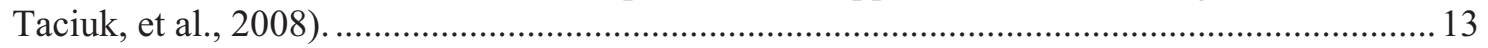

Figure 4. Shell's freeze wall conceptual schematic (from Wong, et. al., 2007).................................... 17

Figure 5. Stratigraphic and hydrostratigraphic relationship at the OST site (Shell, 2006)...................... 19

Figure 6. Schematic drawing of well field configuration of the Shell in-situ conversion process

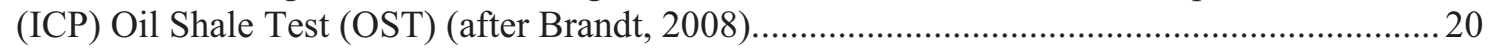

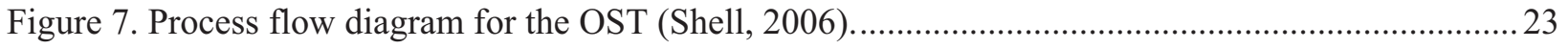




\title{
FY-09 Summary Report to the Office of Petroleum Reserves on the Western Energy Corridor Initiative Activities and Accomplishments
}

\author{
1. ALCES REVIEW
}

\subsection{Summary}

ALCES is a computer program developed to assist decision makers in identifying high-level strategic issues associated with land use and to discover the effects on the landscape associated with multiple uses, such as timber, agriculture, recreation, oil and gas development, etc. ALCES has been used to forecast land use and its effects on the environment in areas ranging from small to large (thousands to millions of acres), with most previous uses of the program examining areas in the province of Alberta, Canada. The program is built in a modular fashion, where modules represent a specific land use or natural process. Many land uses are represented in the program, including activities such as agricultural, urban, forestry, industrial, and energy development and exploration.

This review evaluates the potential application of ALCES to addressing management issues associated with simultaneous development of multiple energy resources in the Western Energy Corridor Initiative (WECI), with a particular focus on oil and gas activities. The work of Hudson (2002) and Van Laake (2002) have been instrumental in preparing this review of ALCES for application to the WECI. This review focuses on the energy-sector sub-model (ESSM) (Stelfox and Farr, 2005) of the ALCES program and evaluates its applicability to aid in planning for the development of resources in the WESTERN ENERGY CORRIDOR.

ALCES is a spatially stratified model, meaning that the location of energy exploration features such as wells or roads are unknown in the analysis performed by the program. The stratification of the sector footprint is by broad land-cover class only. While spatial stratification may not be a limitation of strategic analysis and planning for mixed use between industries such as forestry and agriculture, the assumption of spatial stratification will likely have serious consequences for development of energy resources such as oil and gas, oil shale, and coal. This is due to issues with the spatial and temporal distribution of the resource footprint and the density of the overlapping resources (i.e., competing uses at any given location, some of which may be mutually exclusive). In addition, since the stratification of energy-sector feature footprints over the initial landscape is instrumental in driving future footprints, the availability of a spatial database of very high spatial and temporal accuracy is essential. It is unlikely that the assumptions of spatial stratification and time invariance of the distribution are valid for hydrocarbon resources.

The ESSM represents the energy sector in a mechanistic manner, with an emphasis on the development and persistence of the sector footprint. The structure of the sub-model is likely inadequate to represent the dynamics of oil and gas activities. The exploration and exploitation of hydrocarbons is driven by economics and subsurface geology and, inherently, has a large degree of uncertainty. ALCES does not properly incorporate the characteristics of the particular basin under consideration to guide the development of energy-sector footprint and hydrocarbon production, nor does it consider oil and gas prices that drive the development of the hydrocarbons. Therefore, the ALCES model is not considered to be a suitable tool to forecast hydrocarbon development within the WECI.

\subsection{Introduction}

ALCES is a computer program developed to assist in identifying potential environmental and industrial issues associated with development of mixed (sometimes competing) natural resources and identifying strategies to ensure sustainability of resource development. The ALCES model consists of a number of sub-models, each describing real-world phenomena or processes and their relationship to other 
sub-models. The model makes practically no assumptions about the nature or composition of the landscape or the natural or anthropogenic processes taking place on the land.

Individual areas of land (or specific resource locations) are not tracked in ALCES; instead, classes of land areas are tracked. For land-based systems such as forestry, this implies that the characteristics of land cover classes can be accurately modeled, but not so for the mosaic of land cover patches.

ALCES is a spatially stratified model: footprints are laid out in the landscape according to a proportional distribution by land cover type based on historical footprint distribution of that particular feature. For the energy sector, this means that individual features (well sites, pipelines, well site roads, etc.) are not logically or spatially related to each other (e.g. a pipeline that connects to a gas well), but only proportionally so (a certain length of pipeline is added for each new well). This spatial stratification requires certain premises to be valid, and it has implications on how the energy sector manifests itself in the model. Quality of a spatial database must be adequate to extract relationships between land cover types and the footprint of individual features. In order to use historic footprint distribution over land cover types, efforts must be taken to ensure that they are representative of the future feature-footprint distribution. In addition, global density of footprint distribution by land cover types must adequately mimic actual development in the landscape.

The burden to ascertain that all the relevant components of a system are included in the model and that the relationships between these entities are valid rests with the modeler. The absence of spatial references limits the usefulness of ALCES to those problems in which the relative abundance of modeled resource entities is more important than their position relative to each other, which generally is not the case when dealing with hydrocarbon resources.

The ALCES model is intended to support strategic planning by enabling the rapid evaluation of alternative policies or business strategies, specifically in regard to the effect on the landscape and the production of goods and services. The program requires a planning horizon of no less than approximately five years, with the ability to forecast decades into the future. The model was not developed for operational planning or execution due to the fact that it does not support spatially explicit process management. Also, it does not easily interface with other operational management tools or GIS spatial relationship programs.

\subsubsection{The ALCES model requires extensive amounts of data}

The initialization of ALCES from an empty model to a specified model of a particular study area is not trivial. The amount and breadth of data that are required to run the model with consideration of the main processes taking place in the actual landscape make the collaboration between experts of different disciplines mandatory. In a typical situation, this will require expert assistance as an analyst in the forestry industry will not likely be adequately informed to make assumptions about the energy sector. However, ALCES does provide a collection of statistical data that can guide a user in preparing the data.

Most of the parameters in an ALCES simulation are set to zero initially, effectively rendering any simulation of them impossible. It is left to the user to populate the model with data, which can be an arduous task given the complexity and breadth of the model and the lack of spatial references. However, ALCES does come with some tools to assist in this task. ALCES uses an Excel spreadsheet as an interface for data entry. The data input into the spreadsheet can alternatively be manually entered into ALCES, but the spreadsheet is a much easier interface for storing, modifying, and loading data into ALCES. Still, the large number of parameters that are needed to run a simulation are not very straightforward, and a number of different worksheets (18 total) of the spreadsheet must be completed by specialists in the fields of GIS, forestry, agriculture, economics, etc. The spatial data can require complex preprocessing in order to be rendered into a usable format for ALCES.

The assignment of specific features to land use classes in ALCES is not part of ALCES itself, but must be determined prior to using the classes. Depending on the quality of the spatial database, a more or 
less sophisticated assignment scheme for features can be adopted. For example, when a detailed road network in a study area exists, but without indication of the origin or purpose of the roads (e.g. forest road, wellsite road, backcountry trail), a proper analysis cannot be done to determine a road footprint for individual land uses. However, errors or ambiguity of this type are not attributable to ALCES. They do have implications for the accuracy of the parameter values and, thus, the simulation results. As with all modeling efforts, the burden is on the user to provide the model with reliable data.

ALCES provides data on tree growth trajectories and fire rates, making it easier to establish a working, reliable model and ensuring compatibility between different users of ALCES. Similar standard data arrangements could be made for various aspects of the energy sector (for instance, production per well, SOx/NOx concentration, well-site-pad size, well-site-road width, etc). Such arrangements would go a long way towards ensuring the use of proper assumptions with regards to the effect of the energy sector on the landscape (footprint) and the environment (pollution).

\subsubsection{Data requirements}

ALCES was designed as a landscape simulator. While it is possible to incorporate additional features needed for energy-sector simulations, it is unlikely that sufficient data to populate an enhanced model is available. The current data requirements for energy-sector activity in ALCES are basically the anterior activity, which would typically be stored in a GIS database as a number of features per footprint type and the associated area. This type of data is generally easily attainable for the land managers that typically use ALCES (e.g., forestry and timber). However, the kind of data that is required to support the extension of ALCES to a usable energy-sector model would require the commitment of the energy operators to supply the needed data. In the case of hydrocarbon resource distribution, grade, and quantity, there are a few problems, as this data is relatively sparse as the coverage is not complete throughout the entire WECI.

For the characterization of deposits, the logic (e.g., shape of the curve, size distribution) would be included in the model itself, but it might be necessary to periodically adjust the parameters that describe the shape of the curve due to collection and interpretation of new subsurface data. In addition, the energy sector would need to maintain a registry of deposits such that the discovery curve of particular study areas could be established on the basis of anterior discoveries. All of this would require a substantial and continuous effort on the part of energy operators and regulators.

\subsection{The ESSM in ALCES}

The energy sector operates just like any other sector (agriculture, forestry) in ALCES: through its internal dynamics, it places a footprint on the landscape. However, ALCES is not designed to represent the energy sector in any great detail; only those aspects that produce a significant footprint in the landscape are considered. Much of the complexity of the sector is condensed into a few key components. For example, there is no distinction between drilling for oil or gas in the plains or in the foothills. As long as the dynamics of the two operation modes and their footprint in the landscape are similar, these simplifications are valid, particularly in the context of strategic planning over time scales where operational and tactical considerations do not play a role.

A nine-step approach to populate the ESSM is suggested to simulate different scenarios and to interpret the results. Since this procedure covers almost the entire ESSM, seven of the nine steps are described here to apply the model. The last two steps of the suggested procedure, which deal with the actual simulation and interpreting the simulation results, are not discussed.

1. Defining initial area and length of energy-sector footprints

Populating ALCES with data for the energy sector follows the same process as used with other submodels. The typical characteristic of energy-sector parameters is identification of the land cover type on which the footprint of the energy sector is laid. This is typically done outside of ALCES, and then the ALCES input tables are populated with this data. The features with footprints of the energy sector 
being considered are seismic lines, well sites, pipelines, access roads, surface mines, and processing plants.

2. Defining future trajectories of energy-sector activity

Four future trajectories of the energy sector can be modeled in ALCES. These trajectories are labeled from no growth to high growth, with the trajectories being defined by the user. The four levels of future trends are envisioned to represent the effects of commodity prices, government permissions requirements, and technology development. For each trajectory, the annual number of new wells for oil and gas and heavy oil wells, as well as the annual area of new surface mines, must be specified as a function of time. This data is entered with a typical temporal resolution of ten years, with each future trajectory or scenario run individually.

3. Defining metrics of energy-sector footprints

The dimension of the energy-sector footprint must be specified for each individual resource type as a function of time. ALCES developers recommend that the initial dimensions of the footprints be derived from actual data recorded in the field or taken from a GIS database. The user must extrapolate future trends of the footprints. For example, seismic lines can be grown into the landscape either by entering an average length per resource per time span (e.g., miles per year) or by making the average length a function of number of wells per resource per time span.

For well sites, the average size of the wellpad, the average lifespan of the wellpad, and the number of wells per pad have to be specified for each individual resource type (gas, light oil, heavy oil, and delineation wells) and as a function of time. Well-site-road average length and width and the average life span have to be specified, also as a function of time. The average length of pipeline per well, average total pipeline length and average pipeline width have to be specified, as well as the spatial overlap of pipelines (the degree to which pipelines share a footprint), again as a function of time. All of these footprint data are entered with a typical temporal resolution of ten years.

4. Defining production levels of energy-sector footprints

Defining the production rate of hydrocarbons serves two purposes in ALCES: 1) the production figures are used to calculate the socioeconomic importance of the resource, both in terms of the economic value of the production (direct) and the amount of labor that is needed by the energy sector (indirect), and 2) the figures can be used to calculate the production of $\mathrm{CO}_{2}$ for climate change strategies. For each hydrocarbon resource, the average annual production per well (oil, gas) or acre (coal, oil shale) can be entered as a fixed value over time. These figures are global for the study area and the duration of the simulation, although deposit depletion can optionally be selected.

5. Defining size and change to the hydrocarbon reserves

The recoverable reserve can be entered for each hydrocarbon resource. The reserve is depleted by the production rate per resource, which is defined by the number of wells and their average production rate for gas and oil or the active surface area and mining rate for oil shale and coal. The user has the option of enforcing depletion of the hydrocarbon reserves. If enforced, the reserves will be depleted at the extraction rate dictated by the number of wells and their production rate, per resource. The extraction rate per well is constant until the resource is depleted, upon which the extraction rate becomes zero instantly. If depletion is not enforced, the extraction will continue at the rate set by the extraction capacity. Enforcement of depletion is a function of the time scale considered and the size of the resource.

6. Reclamation trajectory of energy-sector footprints

The energy-sector footprints are assigned an average lifespan. When the lifespan ends, the feature is removed from the landscape, and the footprint reverts to some natural cover type. This reversal can be either random or proportional to the existing cover type. For example, when the footprint reverts from 
a mined cover to a treed cover, the footprint is added back to the area of the first stage of that tree cover type.

7. Simulating employment and revenue associated with the energy sector

Based on the production of oil (all types), gas, and coal, and the average employment per resource, ALCES calculates the employment and wage income generated by the energy sector. However, considerable refinement for unconventional resource development needs and impacts will be required for the socio-economic indicators to be generated with sufficient accuracy in ALCES for application to the WECI.

\subsection{Deficiencies of the ESSM}

A number of deficiencies were identified in the ALCES ESSM model logic in the detailed energysector studies conducted by Hudson (2002) and Van Laake (2002). Two issues were deemed significant, while a third category describes a number of minor issues.

1. Model logic

The two most restricting assumptions of the ESSM in ALCES relate to the proportional stationary and homogeneous nature of the footprint and the mechanistic operating mode of the sector. In ALCES, the footprint of the energy sector is proportionally distributed over the initial land cover types. This proportional distribution is then maintained throughout the simulation. The physical characteristics of hydrocarbon deposits and the temporal characteristics of the energy sector (infrastructure gradually growing into an area) have no relationship to land cover types and, if the distribution of land cover types is non-uniform over the study area, the premise of proportional distribution of the energy-sector footprint by land cover types cannot be maintained. The relevance of the proportional distribution is very evident in the different spacing requirements for different hydrocarbon resources.

Sub-models in ALCES are deterministic; the ESSM always produces identical results when used with identical parameter values. The energy-sector operations are generally unpredictable beyond a year or so, making deterministic predictions difficult. The sector responds rapidly to commodity prices (relative to the typical temporal resolution of ALCES), and exploration has a large element of uncertainty, which drives the establishment and density of drilling operations and the use of pipelines or truck transport of crude.

The implementation of the energy sector in ALCES is not deemed adequate to represent these features of the sector. The interaction of elements of the energy sector is implemented in a mechanistic way: the numbers of seismic lines, well sites, pipelines and well site access roads are tied through proportional relationships. In reality, however, and depending on the characteristics of the exploitation, there might be different proportions of the footprints by resource through time (i.e. the installation of pipeline infrastructure). Also, the life cycle of the deposits being exploited is not considered. In its current implementation, ALCES tracks the total exploitable reserves and the rate of discovery per resource for the entire study area, with the wells extracting constant amounts of hydrocarbons until the exploitable reserve is depleted, modified by a maximum extraction rate.

2. Assumption of uniform distribution in land-cover strata

ALCES assumptions underlying the spatially stratified distribution of energy-sector footprints in the landscape are based on practical considerations, rather than on an objective principle based on the landscape or on an analysis of energy-sector dynamics. The uniform distribution over land-cover types throughout the study area is a significant limitation to the model.

In the case of oil and gas drilling, which is driven by subsurface conditions that have no correlation to land cover types, the distribution is not likely to be uniform over an entire study area. The overall 
pressure on the landscape might be above a certain critical level for some natural system, but the pressure of wells and related infrastructure is largely concentrated in clearly defined areas, with the remainder of the area experiencing much lower levels of pressure. The inability of ALCES to capture this spatial diversity is, by itself, sufficient to invalidate the model as such, when such diverse conditions exist in a single study area.

3. Time required to develop the data sets required to run the model

A considerable amount of data must be gathered, processed and entered into ALCES for the model to run in any meaningful way. However, this criticism could be levied at any other systems dynamic model considered for application by WECI. Indeed, the gathering and processing of the data is likely to require many times the effort required to actually run the model. The data gathering effort, data interpretation, conceptualization of future scenarios and other "preliminary activities" may lead to many insights not currently considered. Data gathering should begin immediately and continue for the duration of the WECI project.

4. Minor issues

Much of the temporal dynamics of the energy sector is captured in graphs. The data in the graphs is static during a parameter-sensitivity analysis. While it is entirely possible to modify the graphs for every individual run of the model and then compare results, it is far less user-friendly than the automated sensitivity analysis.

The use of the four predefined trajectories for resource development growth, based on global energysector dynamics, is implemented in an odd way. Only one of the trajectories can be evaluated at a time, and for this reason, it does not make sense to identify all four scenarios simultaneously. Similar functionality is not found for other sub-sectors in the model. In a typical scenario, these trajectories are run serially, one after another, where relevant parameters are allowed to vary.

\subsection{Conclusions}

ALCES is a model that forecasts natural processes and human activities in the landscape over a period of up to 100 years, with the objective of evaluating different scenarios of land use. In order to do so, it includes sub-models of the most prominent human land use activities, combined with a model of the natural world and its development. The energy sector is also included in ALCES, as certain features of it play an important role in many landscapes.

The relevant features of the energy sector are well represented in ALCES, although their level of detail in the representation is sometimes poor. Certain aspects of some features are not included - for instance special uncertainty in resource quality and quantity - while for others the footprint associated with the feature is too simplistically represented. Of greater concern is the implied dynamics in both exploration and oil and gas drilling activities within the energy sector. ALCES implements these as deterministic processes, which can be simulated over a 100 year time span, while the experts in the energy sector contend that beyond $\sim 5-10$ years into the future, nothing can be said with certainty about the direction or intensity (especially related to resource depletion) of these activities in any particular area.

ALCES assumes a uniform distribution of seismic lines, well sites, pipelines, and other associated features in individual land-cover types in the landscape. From an analytical standpoint, such a claim can only be stated for a specific area at a specific spatial scale, and not as a general rule. The planning and execution of hydrocarbon resource extraction concentrates on areas where resources are likely to be found. The correlation between sub-surface geology and the current landscape may be weak in many cases; therefore, the expression of exploration and drilling for oil and gas in the landscape cannot be assumed to be either uniform or scale invariant.

ALCES is first and foremost a model that tracks change in the landscape, with the objective of building and supporting policies and strategies for a sustainable use of the land-based resources and the 
environmental quality of the landscape. The energy sector is an important player in land use practices, and many land users in different sectors are directly affected by the activities of the energy sector. A complete and accurate representation of the energy sector is therefore of the utmost importance, both for the development of scenarios by those land users and for the development of policies and legislation. Based on the assessment of the ALCES model, the current version of ALCES does not adequately represent parts of the energy sector, particularly the unconventional fossil fuel resources to be directly applied to the WECI.

The ALCES basic structure does provide ample opportunity for an improved consideration of the footprint of the energy sector, as well as its role in the economy and the sustainable use of the natural resources. The authors of the code express a willingness to modify and improve ALCES in ways that could be useful to the WECI. A decade of experience and refinement of the ALCES tool represents an enormous capital investment, and a recommended approach for WECI to support a systems-dynamic model is two fold. First, complete the task of defining energy resources spatially within the Western Energy Corridor. This effort also includes mapping and cataloging a vast array of supporting resources (utility corridors, water resources, wildlife habitat, roads, population centers, etc.) with the intent of eventually entering the data sets into an ALCES type GIS Systems Dynamic Model. Second, begin discussions with the authors of the ALCES code on modifications necessary to improve the usefulness of the code to solving the WECI needs.

\subsection{References}

Hudson, R. J., 2002, An Evaluation of ALCES, A Landscape Cumulative Effects Simulator for use in Integrated Resource Management in Alberta, Discussion paper circulated for by the ALCES Review Team, 31 July 2002,

Stelfox, B. and D. Farr, 2005, A User's Guide to ALCES, A Landscape Cumulative Effects Simulator, DRAFT Version April 9, 2005.

Van Laake, P. E., 2002, ALCES Review, Final Report, Commissioned by Canadian Association of Petroleum Producers, Calgary, Alberta and Department of Energy Government of Alberta, Edmonton, Alberta, May, 2002. 


\section{ASPEN MODELING \\ 2.1 Summary}

\subsection{Background Information}

With the cessation of commercial oil shale development in the 1980's, there were few evolutionary changes to oil shale technologies until interest renewed in recent years. Two exceptions to the 20 -year hiatus in oil shale research include the Alberta Taciuk Process (ATP) and the Shell in-situ conversion process (ICP). The ATP emerged from the need to process and remove organic contaminants from soil for environmental cleanup and from the oil sand process development sponsored by the Province of Alberta. Shell Oil has maintained a long-term view of the potential for oil shale to address peak oil constraints and has continued to fund ICP research and development (R\&D) while most other companies abandoned oil shale R\&D. Both of these technologies have the potential of precipitating major, revolutionary changes in oil shale development technologies. The purpose of information provided in this section is to bring forward the most relevant data and conclusions from publicly available documents on these two technologies in order to assess the feasibility of applying a process simulation code to these processes. Process simulations of these two oil shale processes would aid in understanding and quantifying the energy inputs and outputs, costs, profits, product quality, environmental impacts, and other information needed to make informed decisions regarding oil shale developments in the Western Energy Corridor. One widely employed process simulator is Aspen Plus.

In 2001, INL began modeling of fossil fuel conversion processes using Aspen Plus. Aspen Plus is a steady-state chemical process simulation package originally developed at the Massachusetts Institute of Technology. Included in this package are thermodynamic and physical property data for thousands of organic and inorganic compounds. In addition to the extensive chemical database, detailed mathematical models are included for numerous unit operations, such as heat exchangers, reactors, distillation columns, scrubbers, cyclones, etc. Aspen also includes flexibility to include specialized or unique unit operations by providing links for both Fortran programs and Microsoft Excel spreadsheets. With this underlying foundation, Aspen is well-suited for performing rigorous material and energy balances. Process parameters such as stream composition, temperature, and pressure can be input, and Aspen will calculate outlet composition and conditions for a given unit operation. Unit operations can be combined to represent very complex chemical processes.

Using Aspen Plus as the modeling framework, INL has developed models for numerous fossil fuel conversion processes, including coal to liquids (CTL), coal to methanol, coal to ammonia and urea, coal to substitute natural gas (SNG), integrated gasification combined cycle (IGCC) for power production, biomass gasification, and pyrolysis of municipal solid waste (MSW) and refuse-derived fuel (RDF). During the last three years, Laboratory-directed research and development (LDRD) funding has supported the development of modular code for fossil fuel conversion processes. Specific emphasis has been placed on developing submodels for both the primary conversion technologies and supporting processes, including entrained-flow gasification, fixed-bed gasification, syngas purification with particular emphasis on sulfur removal, cryogenic air separation, elemental sulfur production, Fischer-Tropsch (FT) synthesis, synfuel upgrading and refining, ammonia production, urea production, electrical generation using gas turbines, and electrical generation using steam turbines.

The models developed at INL have been used extensively to support industrial clients in feasibility and pre-FEED studies. A recent example is the CTL process model of the Ohio River Clean Fuels 


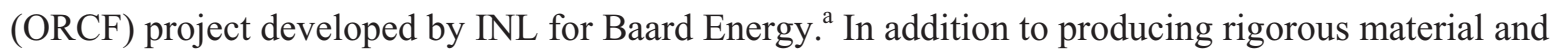
energy balances, the models have been used to support air and water permits. Water consumption for a given plant configuration can be calculated. Carbon balance results from the model can also be utilized for lifecycle greenhouse gas emissions calculations for a given process.

The INL has utilized its expertise in modeling and fossil energy technology to perform two tasks for this project

Task 1 -Oil Shale Processes - Numerous in-situ and ex-situ processes have been proposed for recovery of oil from shale; however, nearly all are proprietary and have very little publicly available information. A literature study was performed to identify the two most promising technologies, including one in-situ and one ex-situ process, the Shell ICP and the ATP, respectively. Task 1 provides a written summary of the literature available that will be necessary for preparing a simulation of each process using Aspen Plus or another numerical code.

Task 2 - Develop a Process Flow Diagram - For each selected technology, a process flow diagram was developed at a suitable process scale. The primary deliverable from Task 2 is a process flow diagram for each selected technology that is the first step in the development of a process model.

\subsubsection{Oil Shale Processes}

Development of oil shale resources fundamentally occurs in three major steps: (1) recovery or extraction from the natural setting, (2) processing to separate organic and inorganic constituents, and (3) upgrading the organic components for further refining into conventional fuels. The physical and chemical nature of oil shale deposits dictates the most appropriate development schemes. For evaluation of ATP and ICP, we focus on Step 2, the processing component. A comprehensive analysis of an oil shale development would also include Steps 1 and 3; however, these steps can be dependent on deposit-specific attributes of a particular resource (depth, grade, saturation, etc.). No one process will be best in all circumstances due to the heterogeneous nature of oil shale. The performance of a process at one location depends on a variety of site-specific factors. In addition to the impact on the yield and quality of final products, many site specific issues also greatly influence economics. Availability of support resources such as electric power, heat, processing water, and reactants for use in upgrading reactions, as well as the nature of resulting environmental impacts and requirements for their control or mitigation, greatly impact the overall success, practicability, and cost of any given approach. Energy and environmental efficiencies of oil shale processing play as important a role as the richness and accessibility of the oil shale resource.

Organic fractions of oil shale are separated from the mineral fraction through a process known as retorting. During retorting, kerogen is released from the mineral surface to which it is adsorbed and subsequently undergoes chemical transformations in a process known as pyrolysis. When ex-situ methods are used, retorting causes thermal desorption of the organic fractions from the mineral fractions and their subsequent destructive distillation or pyrolysis, which produce three product streams: crude shale oil (a collection of condensable organic liquids); flammable hydrogen gases; and char, a solid fraction of organic material that typically remains adsorbed to the mineral fraction of the shale. When in-situ process are employed, only the kerogen or its pyrolysis products are recovered, and any subsequent aboveground retorting is conducted simply to complete kerogen pyrolysis.

There are two types of oil shale retorting processes: ex-situ and in-situ. Ex-situ processes mine the shale and retort it in an above-ground retort. In situ processes apply heat to shale within the geologic formation. Current and historical commercial oil shale operations have been ex-situ, while in-situ processes remain in development (Bartis, et al, 2005). We describe one ex-situ and one in-situ process in the following sections.

a. The ORCF project is currently entering the front-end engineering design (FEED) phase. Two of the three environmental permits for this facility have been approved, with approval of the third permit expected shortly. This is a $\$ 5$ billion project that will produce $53,000 \mathrm{bbl} /$ day of liquid fuels from coal and biomass. 


\subsubsection{Ex-Situ - Taciuk Process}

The Alberta Taciuk Process (ATP) is an ex-situ dry thermal retorting technology for extracting oil from oil sands, oil shale, and other organics-bearing materials, including oil-contaminated soils, sludges, and wastes. The technology is named after its inventor, William Taciuk, and the Alberta Oil Sands Technology and Research Authority (AOSTRA) (Qian and Wang, 2007, Brant, 2009).

\subsubsection{History and Operations}

Research of the ATP technology started in 1970 (NPOSR). In 1975, William Taciuk formed UMATAC Industrial Processes (now part of AECOM) to develop the ATP technology under the sponsorship of AOSTRA (AECOM, 2010). The ATP was originally researched and designed for the extraction of bitumen from tar sands in Canadian tar sands deposits. The first ATP pilot plant was constructed in 1977 (Odut, et al., 2008). However, commercial application of the ATP was first achieved in 1989 in the environmental remediation of contaminated soils (AECOM, 2010).

The ATP process was used to treat over 42,000 tons of PCB-contaminated soils at the Wide Beach Development site in Brant, New York, in May 1991 (EPA, 1992). Three test runs were conducted during the demonstration. Key findings from the Wide Beach site demonstration are summarized below:

- The ATP unit removed PCBs in the contaminated soil to levels below the desired cleanup concentration of $2 \mathrm{ppm}$

- $\quad$ PCB concentrations were reduced from an average concentration of $28.2 \mathrm{ppm}$ in the contaminated feed soil to an average concentration of $0.043 \mathrm{ppm}$ in the treated soil

- The SoilTech ATP does not appear to create dioxins and/or furans

- No volatile or semi-volatile organic degradation products were detected in the treated soil

- There were also no leachable volatile organic compounds (VOCs) or semi-volatile organic compounds (SVOCs) detected in the treated soil

- No operational problems affecting the ATP's ability to treat the contaminated soil were observed.

The ATP process has also been applied to oil shale retorting. In 1999, construction was completed for the $\$ 250$ million (Aus) Stuart Oil Shale Project in Queensland, Australia. The 4,500 bbl/d (715 m²/d) demonstration plant employed the ATP Process and was planned to eventually lead to a commercial scale operation of at least 85,000 bbl/d (13,500 $\left.\mathrm{m}^{3} / \mathrm{d}\right)$ (McFarland and Hopkins, 2000). In early 2001, the plant was restarted after more than $\$ 6$ million (Aus) worth of equipment was installed as part of a program of emission and noise abatement.

Shale was introduced into the ATP Processer at rates of up to $150-160$ tones $/ \mathrm{hr}$. The feed rate represented $60-65 \%$ of plant capacity. Suncor said odor sampling and noise abatement measurement showed improvement over commissioning runs earlier in the year. The Australian partners in the project, Southern Pacific Petroleum, NL, and Central Pacific Petroleum, NL, also reported low levels of dioxins in the plant's air emissions and spent shale. Operations were due to gradually increase in 2001. Partners were planning a second stage with a feed rate of 25,000 tones/day of shale and production of $14,000 \mathrm{bbl} / \mathrm{d}$ of oil. If successful, the Stuart project could have led to an $85,000-b b 1 / d$ operation.

In April 2001, Suncor left the project, and Australian companies Southern Pacific Petroleum, NL, and Central Pacific Minerals, NL (SPP/CPM), became the sole shareholder of the project. In February 2004, the Stuart Oil Shale Project was sold by receivers to the newly formed company Queensland Energy Resources (QER). The plant was shut down on 21 July 2004 because it did not meet environmental and operating performance standards despite having produced and sold over a million barrels of shale oil during 2000-2003 (Wilkinson, 2008a). 
In early August of 2008, QER abandoned the ATP process in favor of the Paraho II technology to develop its oil shale deposits along Queensland's east coast. The company chose Paraho II following assessment of 63 other possible technologies and noting the lessons learned from the Company's decommissioned ATP demonstration plant. QER decided the ATP could not be scaled up to commercialscale production. The ATP plant has been dismantled, and obsolete components sold (Wilkinson, 2008a).

On August 25, 2008 the Queensland government placed a 2-year moratorium on oil shale projects, paralyzing the QER \$14 billion (Aus) Paraho II project. The government representative cited concerns of community and environmental groups who maintain that the Whitsunday region tourism industry and the Great Barrier Reef are at risk if the project proceeded (Wilkinson, 2008b).

UMATAC currently runs an ATP processor at 5 tons of oil shale per hour in Calgary for large scale tests of different oil shales (Parkinson 2006). The Fushun Mining Group of China is building a 250 tones per hour ATP plant (Chandler, 2006, Qian and Wang, 2007, Taciuk, 2008). The ATP was imported to China to handle small particles of oil shale (Li, et al., 2008).

After a review of more than 60 oil shale processing technologies, Jordan Energy and Mining, Ltd., has opted to employ the ATP for extracting of Al Lajjun and Attarat oil shale deposits in Jordan. The company cited the 33 year track record of ATP and concluded that it is the best available technology for Jordanian oil shale (JEM, 2010). Jordan Energy and Mining, Ltd., plans to build two $500 \mathrm{ton} / \mathrm{hr}$ ATP retorts to simultaneously extract and perform the primary upgrade of the oil recovered from the oil shale.

\subsection{Process}

The ATP is a dry thermal process involving indirect heating of oil shale using countercurrent gas-solid heat exchange as well as the generation of process heat by combustion of coke (carbon present on retorted oil shale solids) in the combustion zone of the kiln. The ATP provides high heat-transfer efficiencies and integral combustion of coke for process-heat demands, which minimizes the amount of residual coke remaining on spent shale. This combination minimizes $\mathrm{CO}_{2}$ release per ton of shale processed and reduces the potential for environmental contamination from improper spent-shale disposal (DOE 2004). The distinguishing feature of the ATP is that the drying and pyrolysis of the feed oil shale material and the combustion, recycling, and cooling of spent shale all occur in a single rotating multichamber horizontal retort (Qian and Wang, 2007, AECOM, 2010). It has lower water requirements than previous surface retort designs, and unlike some other retort designs like the vertical shaft kiln, it can utilize fine particles, thus reducing shale waste. In addition, most or all of the retorting energy is provided by the combustion of char and produced gas. Once operating, no external energy sources are needed to stimulate the reactions in the retort apart from a modest amount of electrical power to rotate the retort and power the upgrading system (Schmidt, 2003).

It is classified as a hot recycled-solids retort, meaning that heat is transferred to fresh shale from hot, already-retorted shale that is recycled into the retorting zone. The retort is operated slightly below atmospheric pressure to prevent escape of explosive gases (-30 to -50 Pa15). The primary unit is the ATP processor, which is a modified horizontal rotary kiln, and it works in conjunction with a number of ancillary subsystems that, together, comprise the ATP System. The ATP processor has four internal zones in which the four stages of ore processing occur: (1) preheating of the feedstock, (2) pyrolysis of the oil shale under anaerobic conditions, (3) combustion of coked solids to provide the process heat requirements, and (4) cooling of the combustion products by heat transfer to the incoming feed. The ATP System provides more than simple retorting; the processor, together with its subsystems, can provide primary upgrading of the initial retort products, as well as capture and control of problematic by-products.

A schematic flow diagram of the ATP System is shown in Figure 1, and a representation of the ATP processor is shown in Figure 2. Oil shale particles less than 25 millimetres (1.0 in.) are fed into the drying zone of the retort where they are preheated and dried indirectly by hot shale ash and hot flue gas (Qian and Wang, 2007). In the reaction zone, oil shale particles are mixed with hot shale ash, and the pyrolysis 
occurs at the temperature of $500^{\circ} \mathrm{C}\left(930^{\circ} \mathrm{F}\right)$ to $550^{\circ} \mathrm{C}\left(1,020^{\circ} \mathrm{F}\right)$. The hydrocarbon vapors evolve from the retort and are recovered by condensation. Residue coked solids are moved to the combustion zone where they are burnt at a temperature of about $800^{\circ} \mathrm{C}\left(1,470^{\circ} \mathrm{F}\right)$ to form shale ash. Part of the ash is recycled to the pyrolysis zone where it acts as hot solid carrier for oil shale pyrolysis; the remaining spent shale is removed (Qian and Wang, 2007, Brandt, 2009).

The advantage of the ATP technology for shale oil extraction is its simple and robust design, energy self-sufficiency, minimal process-water requirements, ability to handle fine particles, and high oil yields (NPOSR, 2004). It is particularly suited for processing materials with otherwise low oil yield (Õpik, 1999). It allows the mechanical transfer of solids through the machine with no moving parts and achieves improved process efficiencies through solid-to-solid heat transfer (NPOSR, 2004). Most of the process energy (over $80 \%$ ) is produced by combustion of char and produced oil shale gas; external energy input is minimal (Brandt, 2009). The oil yield is designed to be about 85-90\% of Fischer Assay (Qian and Wang, 2007). The process residue (spent shale) consists of total organic carbon less than 3\% (NPOSR, 2004). The process produces only small amounts of contaminated water with low concentration of phenols (Mölder, 2004). Similar advantages apply to the oil sands' extraction, including increased oil yield, a simplified process flow, reduction of bitumen losses to tailings, elimination of the need for tailings ponds, improvement in energy efficiency compared with the hot water extraction process, and elimination of requirements for chemical and other additives (DOI, 2007).

A complication of the ATP is that retorting operations can reach temperatures at which carbonate minerals within the shale decompose, which increase greenhouse-gas emissions (Brandt, 2009).

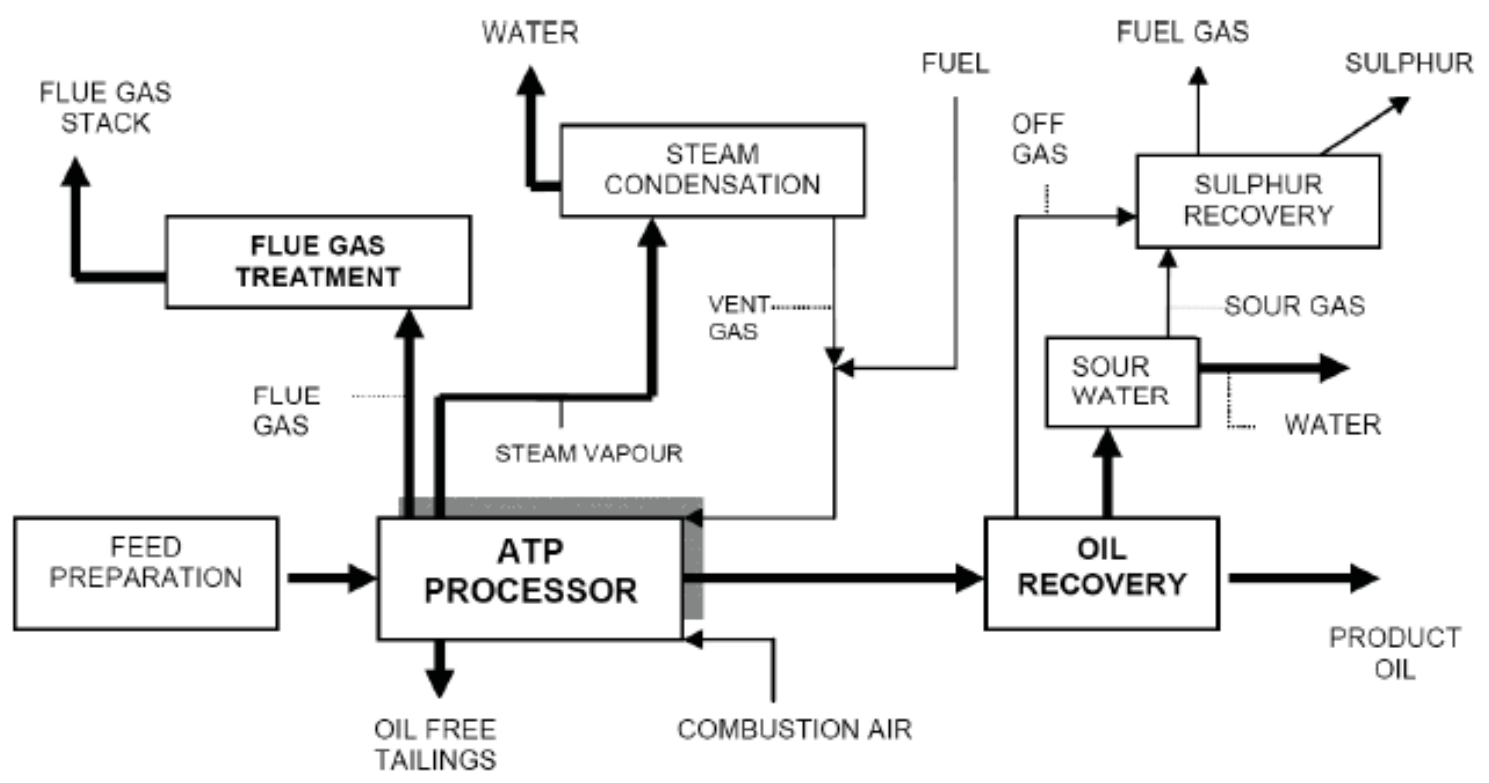

Figure 1. ATP System flow diagram processor (Source: DOI, 2007). 


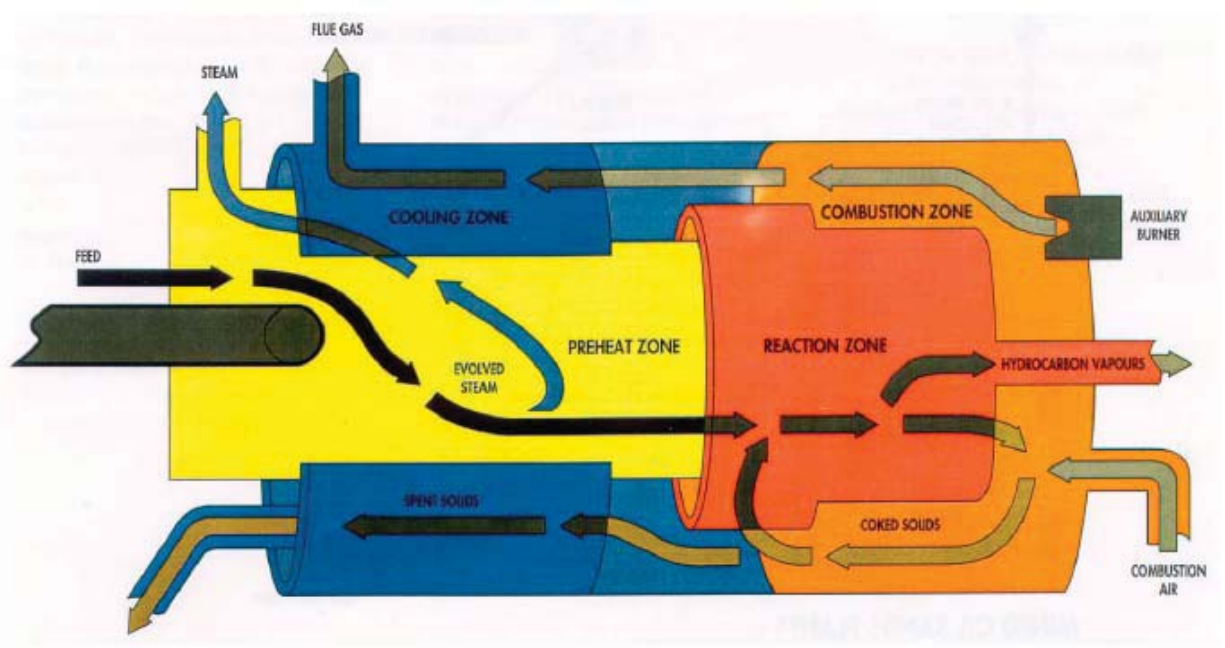

Figure 2. Pictorial representation of ATP Processor (Source: Taciuk, 2008).

\subsection{Summary}

Figure 3 presents a flow diagram for the ATP process with the core ATP processes highlighted in yellow. The ancillary sub-processes outside the ATP processor are common industry processes that have analogs that will aid in model development. It is proposed that Aspen Plus modeling address the core ATP processes. A significant advance for the Western Energy Corridor Initiative is definition of the mass inputs and outputs for ATP processor. The process mass balance will aid in understanding and quantifying the costs, profits, product quality, water consumption/degradation, air impacts and other information critical for understanding the costs and benefits of oil shale development.

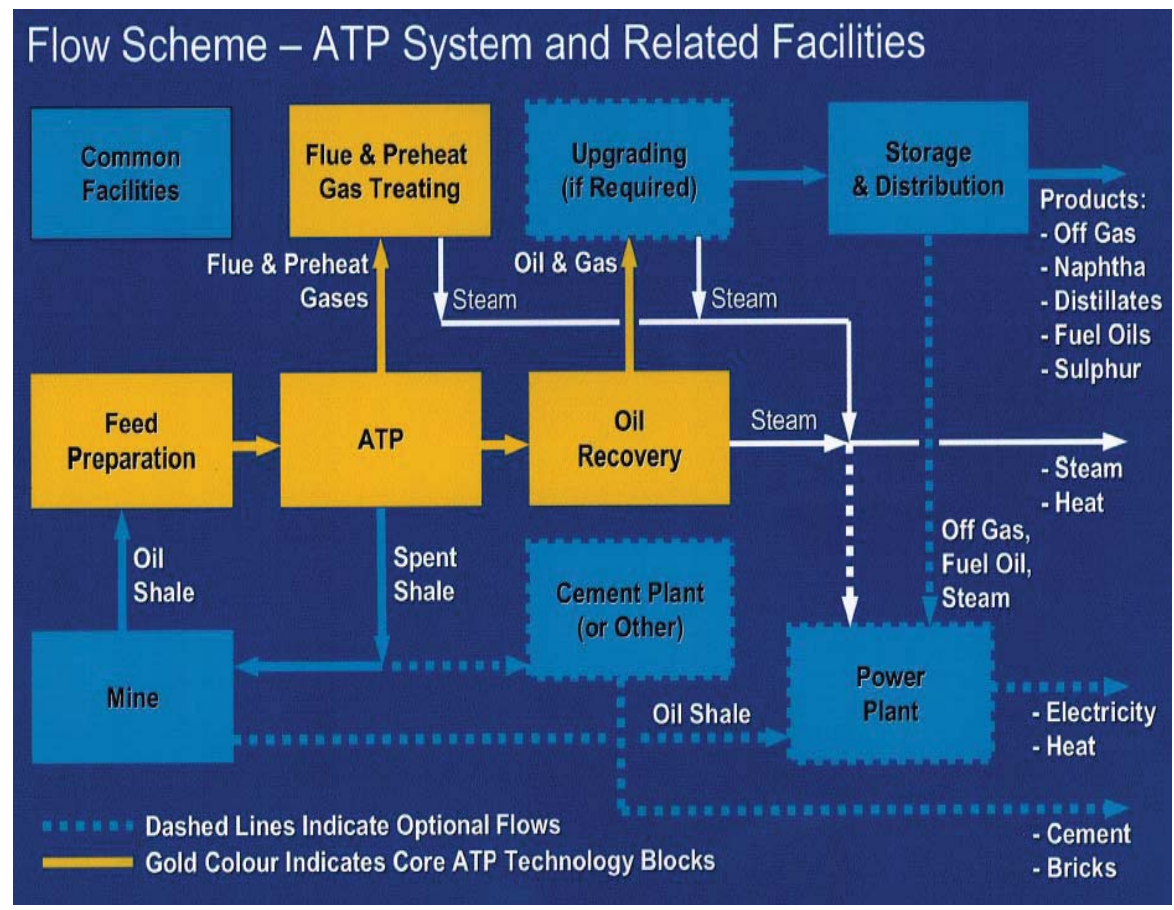

Figure 3. Flow schematic for the ATP and related processes to support oil shale retorting (from Taciuk, et al., 2008). 


\subsection{References}

"Stuart Oil Shale project ready for restart". Alexander's Gas \& Oil Connections. 2000-01-31. http://www.gasandoil.com/goc/company/cns01260.htm. Retrieved 2008-12-25.

AECOM, 2010, "UMATAC and the Alberta Taciuk Process". AECOM Technology Group. http://aecomdev.guidance.com/aecomcmsprod8/content/preview? contentId $=4556 \&$ viewId=10301006\& contentTypeId $=1030104$. Retrieved 2010-01-09.

AERI, 2007, "AOSTRA-Taciuk Process (ATP)". Alberta Energy Research Institute. http://www.aeri.ab.ca/sec/suc_sto/suc_sto_001_3.cfm. Retrieved 2010-1-9.

Bartis, J. T.; et al., Oil shale in the United States: Prospects and policy issues; RAND: Infrastructure, Safety and Environment; RAND: Santa Monica, CA, 2005.

Brandt, Adam R, 2009, "Converting Green River oil shale to liquid fuels with the Alberta Taciuk Processor: energy inputs and greenhouse gas emissions", Energy Fuels, 2009, 23, 6253-6258, SOI.10.1021/ef900678d.

Chandler, Graham (2006). "US eyes Alberta as model for developing oil shale". Alberta Oil Magazine 2 (4): 16-18.

DOI, 2007, Draft Oil Shale and Tar Sands Resource Management Plan Amendments to Address Land Use Allocations in Colorado, Utah, and Wyoming and Programmatic Environmental Impact Statement, Tar sands development background and technology overview. Appendix B. U.S. Department of the Interior, Bureau of Land Management, DES 07-06, December 2007.

EPA, 1992, AOSTRA-SoilTech Anaerobic Thermal Processor: Wide Beach Development Site, SoilTech ATP Systems, Inc., Site Superfund Innovative Technology Evaluation Demonstration Bulletin, U.S. Environmental Protection Agency, EPA/540/MR-92/008 March 1992.

JEM,2010, "Efficient Processing Technology". Jordan Energy and Mining Limited. http://www.jeml.co.uk/keyprojects/processingtechnology/. Retrieved 2010-1-9.

Li, S. Y., C.T. Yue and J.L.Qian, 2008, Recent Chinese Oil Shale Activities, 28th Oil Shale Symposium. Golden, Colorado, Colorado School of Mines.

McFarland, J.D. and P.D. Hopkins, 2000, The Stuart Oil Shale Project, SPE Asia Pacific Oil and Gas Conference and Exhibition, 16-18 October 2000, Brisbane, Australia, DOI: 10.2118/64455-MS.

Mölder, Leevi (2004). "Estonian Oil Shale Retorting Industry at a Crossroads" (PDF). Oil Shale. A Scientific-Technical Journal (Estonian Academy Publishers) 21 (2): 97-98. ISSN 0208-189X. http://www.kirj.ee/public/oilshale/1_ed_page_2004_2.pdf. Retrieved 2008-12-25.

NPOSR, 2004, "Strategic Significance of America's Oil Shale Resource.” Volume II Oil Shale Resources, Technology and Economics, Office of Naval Petroleum and Oil Shale Reserves, United States Department of Energy. March 2004.

Odut, Steven, et al., 2008, "Alberta Taciuk Process (ATP) Technology - Recent Developments and Activities", 28th Oil Shale Symposium. Golden, Colorado, Colorado School of Mines.

Õpik, Ilmar (1999). "Black scenario of oil shale power generating in Estonia". Oil Shale. A ScientificTechnical Journal (Estonian Academy Publishers) 16 (3): 193-196. ISSN 0208-189X. http://www.kirj.ee/public/oilshale/ed-page6.html. Retrieved 2008-12-25.

Parkinson, Gerald (2006). "Oil Shale: The U.S. Takes Another Look at a Huge Domestic Resource". Chemical Engineering Progress 102 (7): 7-10. 
Qian, Jialin and Wang Jianqiu, 2006, "World oil shale retorting technologies", Paper No. rtos-A118, International Oil Shale Conference,7-9 November, 2006, Amman, Jordan:

Schmidt, S., 2003, New Directions for Shale Oil: Path to a secure New Oil Supply Well into this Century, Oil Shale, Vol. 20, No. 3, Special, pp. 333-346.

Taciuk, William et al., 2008, Alberta Taciuk Process (ATP) Technology - Recent Developments and Activities, $28^{\text {th }}$ Oil Shale Symposium, October 13-15, 2008, Golden, Colorado.

Wilkinson, R., 2008a, Queensland oil shale project still in the wings, Oil\&Gas Journal, August 15, 2008.

Wilkinson, R., 2008b, Queensland bans oil shale projects for 2 years, Oil\&Gas Journal, August 25, 2008. 


\section{IN-SITU - SHELL IN-SITU CONVERSION PROCESS}

Shell Frontier Oil and Gas, Inc., (Shell) has been conducting research on in-situ conversion process (ICP) for the past 20 years, a highly novel approach to in-situ retorting and directly extracting oil-shale distillates. The ICP uses electric heaters (or other types of heaters) to heat the oil shale in place. The heating process pyrolyzes the organic matter in the oil shale and converts it into oil and gas. The oil and gas are then removed from the ground using conventional oil-field pumping and extraction technology and processed using conventional oil and gas processing. The recovery is conducted within a contained area to allow recovery of the hydrocarbons while excluding ground water flow through the oil production area. Containment is provided by a freeze wall around the perimeter and naturally occurring low permeability barriers above and below the oil shale resource zone (Shell, 2006).

An operation producing 100,000 barrels a day would require a dedicated power generating capacity of 1.2 gigawatts (Bartis, et al., 2005). If this amount of electricity to be generated by coal-fired power plant, it would consume five million tons of coal annually (Farkas, 2008). Although this method is energyintensive, it compares well to heavy oil projects such as oil sands development. Over the project life cycle, Shell estimates that for every unit of energy consumed, three to four units would be produced (Shell, 2006 and NPOSR, 2007). The Energy Return on Energy Invested (EROEI) is low compared to conventional crude oil extraction; however, the heating process itself creates a byproduct of shale gas that can be used as the energy input.

\subsection{History and Operations}

Shell's oil shale research dates back to 1974, when the federal government agreed to lease two tracks of land to Shell in the Piceance Creek Basin (Shell, 2010a). During the 1980's, Shell conducted laboratory experimental research and began to develop the ICP concept (Bartis, et al., 2005). In 1997 and 1998, the first small scale in-situ heating process test was conducted on Shell's 20,000-acre Cathedral Bluffs property near Parachute (Rio Blanco County), Colorado, in the Piceance Creek Basin. The test recovery efficiency was reported as $60-70 \%$ for the liquid phase (Vinegar, 2006). Shell reports recovering 1,700 barrels of high quality light oil plus associated gas (Shell, 2010b) from the $30 \times 40$ foot testing area. More field experiments were conducted in 1999 to collect data in support of geomechanical models, heater development and product transport models.

Beginning in 2001, additional research and development activities were carried on by Shell as a part of the Mahogany Development Project (MDP) to evaluate containment and reclamation techniques (Lee et al., 2007). The containment area for the MDP was $25 \mathrm{ft}$ in diameter and $1450 \mathrm{ft}$ deep and enclosed 712,000 cubic feet of rock containing 18,500 gallons of water (McKinzie et al., 2008). A total of 47 wells were drilled in concentric rings for the MDP. The well types included heater, producer, freeze wall, monitor, and temperature wells. Freezing began in 2002, followed by a series of tests to verify hydraulic containment. Testing after freeze wall completion included filling the containment volume with water to land surface and then removing the interior water. Water levels outside the freeze wall were not affected, verifying that water cannot enter the container and contaminates cannot exit (McKinzie, et al., 2008). Heating of the oil shale at the MDP started in June of 2003 (Reiss, 2005). Heating ended in November 2003, and cleaning of the containment volume began immediately thereafter (McKinzie et al., 2008). Cleaning of the containment zone includes the injection of water to create steam stripping of the VOCs. It is not clear from the open literature how many pore volumes were cycled through the containment zone. Cleaning ended in February of 2004, and Shell received permission to melt the ice wall in October of 2004 from the regulatory authorities, suggesting that cleaning of the containment zone to regulatory levels was successful (McKinzie, 2008).

In 2005, Shell began construction of the Freeze Wall Test (FWT) on a 15-acre parcel of Shell's private property in Rio Blanco County, Colorado. The objective of the FWT is to form an underground barrier to protect groundwater and isolate any proposed ICP production area (Vinegar, 2006). The test 
area is football-field sized area, consisting of 157 freeze holes drilled to $1800 \mathrm{ft}$ and spaced approximately eight feet apart (Deeg et al., 2008). A closed system of refrigeration pipes is networked through the well field in order to create an impermeable frozen barrier. Aqueous ammonia, a common refrigerant, is circulated through the closed-loop pipe system, causing the water in the surrounding rock to freeze and form the underground impermeable barrier (Deeg et al., 2008). At the time of this writing (2010), Shell is continuing to operate the FWT.

\subsection{Process}

Documentation of the details of the ICP is somewhat problematic because it is a proprietary process and a research project. Shell has more than 200 patents recorded on thousands of page, which are not generally useful for reconstructing the details of any specific embodiment of the ICP because they describe multiple incarnations of the ICP, with data fragmented across many patents. Furthermore, the ICP has evolved based on feedback Shell has obtained from laboratory and field tests, and ICP designs change over time. The information presented here is based on the Oil Shale Test (OST) Project, which is a subcommercial-scale test of the ICP that has been documented in scientific presentations and regulatory documents (Shell, 2006).

The ICP process consists of four main steps (refer to the schematic in Figure 4). First, a freeze wall is created around the perimeter of an area of shale to be retorted to create a production "cell." Next, the oil shale within the cell is heated using electric resistance heating. The heat conducts through the formation, slowly heating the shale to the temperature of kerogen decomposition. After kerogen conversion, the resulting HCs are pumped from the earth. Last, the production cell undergoes remediation: residual mobile HCs are flushed from the earth and the freeze wall is thawed.

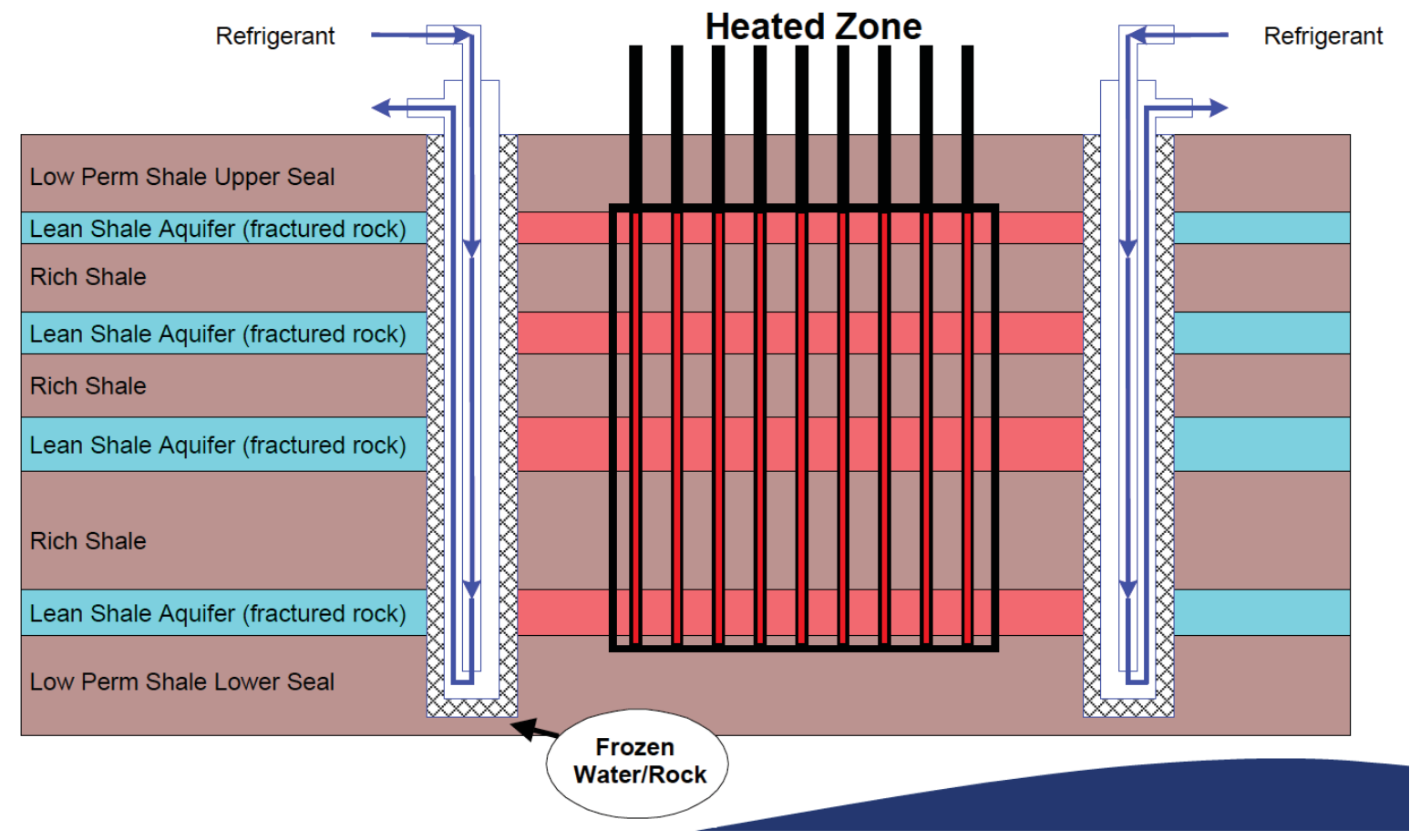

Figure 4. Shell's freeze wall conceptual schematic (from Wong, et. al., 2007).

Ideally, the site for the ICP will be chosen so that a production cell can be "sandwiched" between thick layers of shale with low permeability on the top and bottom. At the OST site, Shell considers the R-7 through R-2 interval of the Parachute Creek Member of the Green River Formation as the resource interval of interest for oil shale development (Figure 5). The total oil-in-place resource is estimated to be 300 million barrels beneath this tract (Shell, 2006). The target oil shale, buried under $270 \mathrm{~m}(870 \mathrm{ft})$ inert 
overburden, is $320 \mathrm{~m}(1020 \mathrm{ft})$ thick (Shell, 2006). The ICP will be isolated between the R-7 Seal and the L-2/R-2 Seal (Figure 5).

\subsubsection{Freeze Wall}

Ground freezing is a common approach employed to exclude water from areas being excavated, to seal tunnels, mine shafts, or other subsurface structures against flooding from ground water; and to enclose and/or consolidate hazardous or radioactive contaminants during remediation or reclamation operations (Sanger and Sayles, 1979). Construction of a freeze wall around the OST will allow heating of oil shale to recover products while preventing mixing of products with the ground water system (Bartis, et al., 2005). A freeze wall will be established for the depth of the freeze holes and will encircle the resource target zone, creating an enclosed freeze wall. The top and bottom of zone are contained by the low permeability layers, preventing hydrocarbon movement in the vertical direction.

The freeze wall for the OST will consist of a series of drill holes in a close pattern, to enclose an area

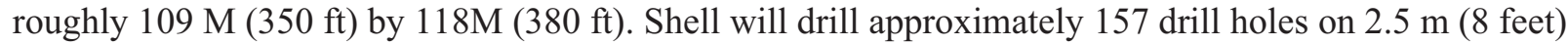
centers around the perimeter of the OST. The freeze holes will be drilled to a depth of approximately 579 $\mathrm{m}(1,900)$ feet, or the depth of the entire target interval (Shell, 2006). A conceptual configuration of the proposed well field is presented in Figure 6. The freeze wall will provide lateral containment to prevent liquid movement into or out of the volume of earth being heated, thus separating the ground water system from the ICP products. The freeze wall will be maintained in a frozen condition throughout heating, recovery, and ground water reclamation operations until it can be demonstrated that the containment cell water meets appropriate quality standards, which will last 10 to 11 years for the OST (Shell, 2006). To maximize the functionality of the freeze walls in full scale application, adjacent working zones will be developed in succession so that adjacent "cells" can share freeze walls. Refrigerant will be circulated through the holes in a closed circuit to create a barrier of frozen water in a rock matrix.

A chilled aqua ammonia solution (refrigerant), at an approximate temperature of $-40^{\circ} \mathrm{C}\left(-45^{\circ} \mathrm{F}\right)$ will be pumped through the holes (Shell, 2006, NPOSR, 2007 and Speight, 2008). The aqua ammonia solution will be circulated at approximately 50 gallons per minute $(\mathrm{gpm})$ per hole. The area immediately surrounding the holes will freeze first. The frozen area will continue to expand as refrigerant is recirculated down each hole. Eventually the frozen "columns" will expand to the point where concentric frozen "columns" are joined, creating the freeze wall barrier. As the circulation of refrigerant continues, the thickness of the freeze wall will continue to grow, although the rate of growth will slow as the wall thickens (the final wall thickness for the OST is estimated as $3.1 \mathrm{~m} \mathrm{(10} \mathrm{ft).} \mathrm{It} \mathrm{is} \mathrm{anticipated} \mathrm{to} \mathrm{take}$ approximately 18 months to establish a continuous freeze wall barrier. Once the freeze wall is in place, there will be little change in the temperature and thickness of the wall because of the insulating capacity of the rock matrix (Shell, 2006).

Once the freeze wall is established, a series of dewatering holes will be drilled in the interior of the containment area to recover, first, water, and then hydrocarbon products. Water from dewatering the freeze wall containment area will be re-injected outside the freeze wall into the appropriate water-bearing zones so that existing water quality is not impacted. Removal of the ground water prior to heating will prevent mixing of the hydrocarbons and ground water and reduce the heat energy required for conversion. Because water has a heat capacity four times that of shale, efficiency requires the removal of as much water as possible (Hendrickson, 1975). After all drainable water has been removed, water will occupy $\sim 7 \%$ of cell bulk volume (Shell, 2006). 


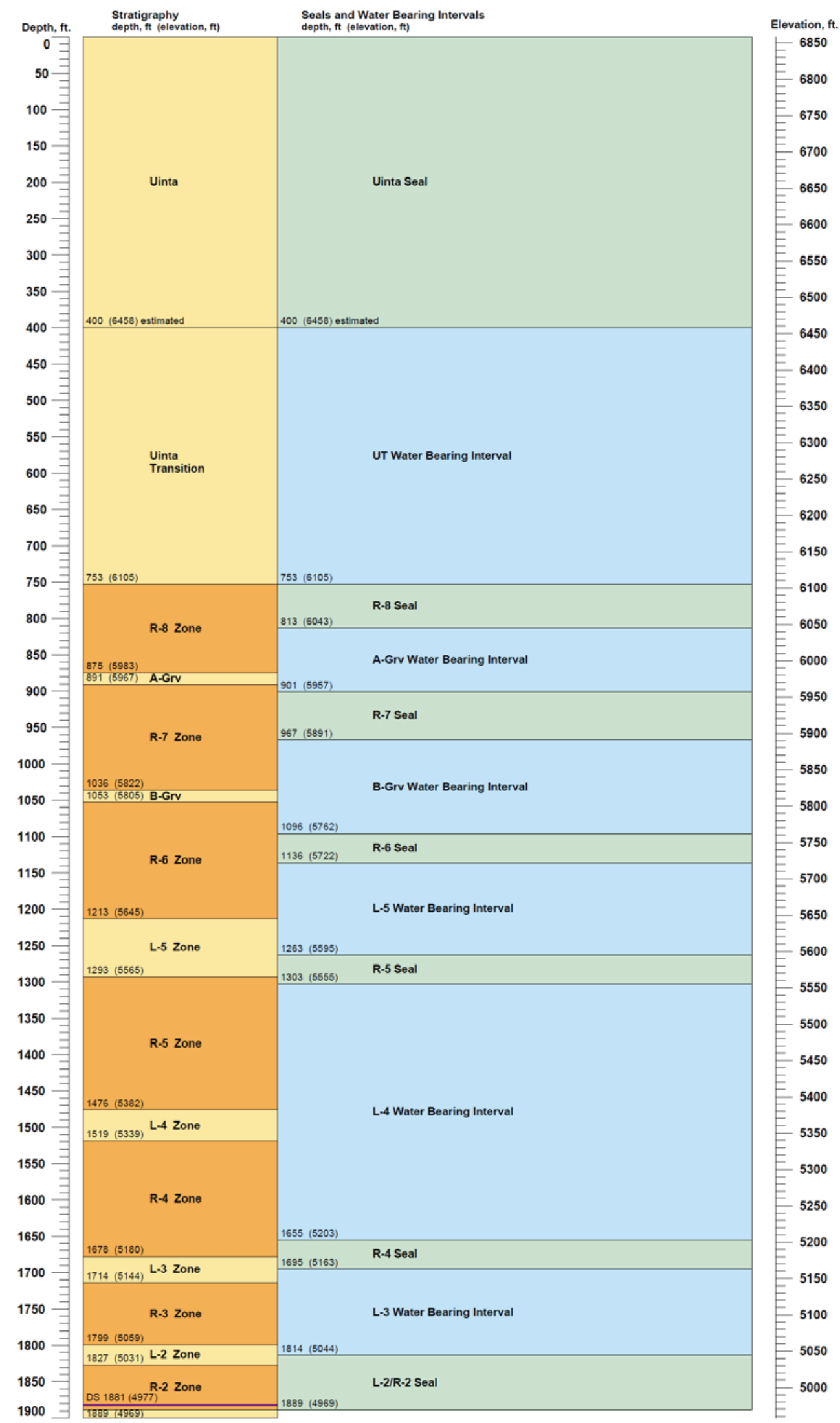

Figure 5. Stratigraphic and hydrostratigraphic relationship at the OST site (Shell, 2006). 


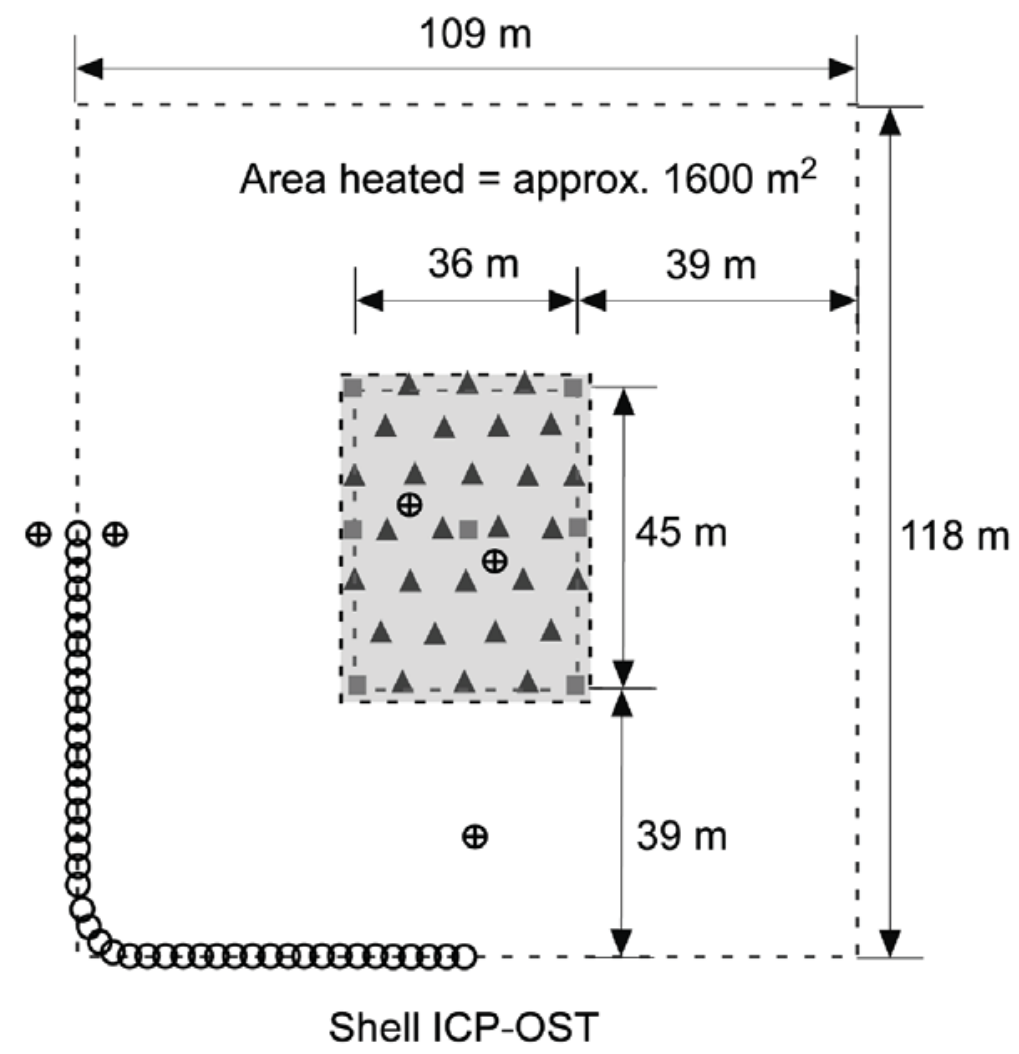

\begin{tabular}{|llll}
\hline . & Production and de-watering wells & $\oplus \quad$ Monitoring well (temp., groundwater) \\
0 & Freeze-wall well (frozen radius of $3.1 \mathrm{~m}$ ) & $\ldots$. & Heater well \\
$\vdots$ & Outline of pattern (heater or freeze wall) & $\vdots$ & Assumed heated area
\end{tabular}

Figure 6. Schematic drawing of well field configuration of the Shell in-situ conversion process (ICP) Oil Shale Test (OST) (after Brandt, 2008).

\subsubsection{Heating}

Approximately 30 heater holes will also drilled within the interior freeze wall containment area, spaced approximately 25 feet $(7.6 \mathrm{~m})$ apart. The spacing of heater wells is a tradeoff: closer well spacing allows the shale to be heated more quickly, but increases drilling costs (Burnham and McConaghy, 2006). The approximate surface area of the heated pattern will be $150 \mathrm{ft}(45 \mathrm{~m})$ by $100 \mathrm{ft}(30 \mathrm{~m})$. A buffer of 38 $\mathrm{m}(125 \mathrm{ft})$ of unheated formation will be preserved between the freeze wall barrier and the heated zone so that the freeze wall is not impacted by heating (Figure 6). Electric heaters will be installed in each hole to uniformly heat the oil shale. The heaters will raise the temperature of the oil shale and initiate pyrolysis, releasing hydrocarbon products that are then removed using the production holes.

Electrical heating elements will heat the oil shale to between $650^{\circ} \mathrm{F}\left(340^{\circ} \mathrm{C}\right)$ and $700^{\circ} \mathrm{F}\left(370^{\circ} \mathrm{C}\right)$ over a period of approximately four years (Shell, 2006 and Lee, et al., 2007). Kerogen in oil shale will slowly convert into shale oil and gases, which then flow to the surface through recovery wells (Shell, 2006 and NPOSR, 2007). The rate of heating can vary, and the temperature at which oil generation is complete decreases as the rate of heating slows. Therefore, it is more thermally efficient to heat the shale slowly (Burnham and McConaghy, 2006 and Burnham, 1993). At atmospheric pressure and a $3^{\circ} \mathrm{C}$ increase per month, kerogen conversion is essentially complete at $300^{\circ} \mathrm{C}$, while at a $3^{\circ} \mathrm{C}$ increase per day, conversion 
is not complete until $350^{\circ} \mathrm{C}$ (Burnham and McConaghy, 2006 and Burnham, 1993). The rate of heating in the OST is estimated to be $\sim 0.5^{\circ} \mathrm{C}$ per day $\left(\sim 350^{\circ} \mathrm{C}\right.$ increase over a two-year period).

During heating, the heat is transferred in the rock formation by thermal conduction only - no steam or heat-transfer fluids are injected into the oil shale. The superposition or overlapping of heat from the array of heaters causes the average resource target zone temperature to rise quite uniformly, except within a few feet of the heater holes (Shell, 2006). Heat loss to the overburden is relatively small. Shell models project a temperature increase of $17^{\circ} \mathrm{C}$ at a point $16 \mathrm{~m}$ above the top of the heated layer at the conclusion of heating (Shell, 2006). Heating also occurs outside of the perimeter of the heater well pattern. Some of this heat results in kerogen conversion, and some is wasted. In models of the OST, conversion is predicted 3$5 \mathrm{~m}$ outside of pattern after 900 days (Brandt, 2006). Waste heating begins beyond this point and extends toward the freeze wall.

Heating can cause the formation to heave and, subsequently after product recovery, subsidence can occur at the surface, and compaction can occur within the reservoir. Shell's modeling, based upon the small production footprint and the depth of heating for the OST, indicates that little expression of changes within the pyrolyzed zone will be apparent at land surface. The surface expressions of heave is expected to be approximately 1.0-1.5 inch, and the surface expression of subsidence is expected to be approximately $0.5-1.0$ inch (Shell, 2006).

\subsubsection{Hydrocarbon Recovery}

Ten producer wells for the OST will collect the gas and oil produced by the ICP. The locations of the producer wells are shown in Figure 6. The producer holes are drilled to a depth of approximately 1,675 feet. Pumps will be installed in each hole to bring the product to the surface. Each producer hole will be equipped with instrumentation to monitor production and reservoir condition, performance, temperature, rates, and pressure as part of the ongoing research efforts at OST (Shell, 2006).

As heating occurs, the lighter and higher-quality vaporized ICP products, plus steam and noncondensable gases, will flow to the producer holes. The initial reservoir permeability required for fluid transport to the wells is likely to be relatively low. However, because of the slow heating rate and the close spacing between holes, there is no need to create permeability by hydraulic or explosive fracturing. Shell states that sufficient permeability exists so that the producer wells will collect the converted kerogen products (oil and gas mixed with some water) in the pyrolyzed zone and convey those products to the surface for transport to the processing facilities (Shell, 2006).

With continued heating, long-chain, heavy hydrocarbons remain in the formation or are cracked. Hydrocarbons travel toward the production wells and are pumped from the earth as liquid at a temperature of $\sim 200^{\circ} \mathrm{C}$ using standard oil production techniques. Shell reports extracting a $34^{\circ}$ API product, consisting of a gas (propane and butane) and liquids split 30\% naphtha, 30\% jet fuel, 30\% diesel, and 10\% slightly heavier oil. Sulfur content was $0.8 \%$ by weight (Savage, 2005). However, the open literature suggests that the amount and type of hydrocarbons produced from the ICP is less certain, and published figures are in some disagreement (Burnham and McConaghy, 2006). Laboratory studies have shown that oil yield is lower if the retorting is done slowly, at low temperature, or at higher pressure (Burnham, 1993). The ICP has these characteristics. Oil yields of 80 vol\% of Fisher Assay yield were found, given an ICP-like heating rate and atmospheric pressure, and yields as low as $60 \%$ occur at higher pressures (Berchenko, I.; et al., 2006). From test plots, Shell reports oil yields of $\sim 66 \%$ of Fisher Assay oil yield (Shell, 2006). In the Fisher Assay, $\sim 7 \%$ of the total energetic yield is gas, with the remainder being oil and char. Slow, high-pressure heating, such as that in the ICP process, results in the production of more gas (Bae, 1969 and Burnham and Singleton, 1983), although published data are sparse. Last, Shell does not state if their yield figures represent oil generated or oil actually produced from the well bore. 


\subsubsection{Reclamation and Remediation}

After oil production ceases, the area within the freeze wall containment area contains residual pyrolysis products. These are removed through flushing prior to allowing the freeze wall barrier to thaw. The water used for rinsing is treated in an on-site ground water reclamation treatment plant, then recycled as rinse water. Some HCs will remain, trapped in a largely immobile state in rock pores. Shell claims that contaminant concentrations will decrease to allowable limits after flushing with 20 pore volumes of water (Shell, 2006). For the OST, Shell plans to haul the waste from the ground water reclamation treatment plant off site. The reject brine solution from the ground water reclamation treatment plant will be disposed in an on-site evaporation pond. When the confinement zone is sufficiently rinsed and the collected rinse water meets appropriate quality, the freeze wall barrier will be allowed to thaw.

\subsection{Summary}

Figure 7 presents a process flow diagram for the ICP process as defined by Shell for the OST. As can be seen, Shell has lumped all of the in-situ conversion processes into the block labeled "Field" in the upper left hand corner of the diagram. What remains are the ancillary sub-processes above ground that are common industry processes. Aspen Plus modeling of the above ground process is relatively straightforward because the simulator has imbedded subroutines that can address the energy balance. What is needed to advance the Western Energy Corridor Initiative is definition of the mass inputs and outputs for the below grade ICP. Shell has carefully guarded the details of the ICP so that it is not possible to rigorously understand and quantify the costs, profits, product quality, water consumption/degradation, air impacts and other information critical for understanding the costs and benefits of ICP. However, the INL and other research organizations have undertaken bench-scale laboratory test that can aid in reducing uncertainty in Aspen Modeling of the ICP. More information can be taken from the open literature on freeze-wall construction for building foundation dewatering projects. It appears feasible to prepare an Aspen Plus model of the ICP, but it must be recognized that significant uncertainty will be associated with the output until data are available from field testing. 


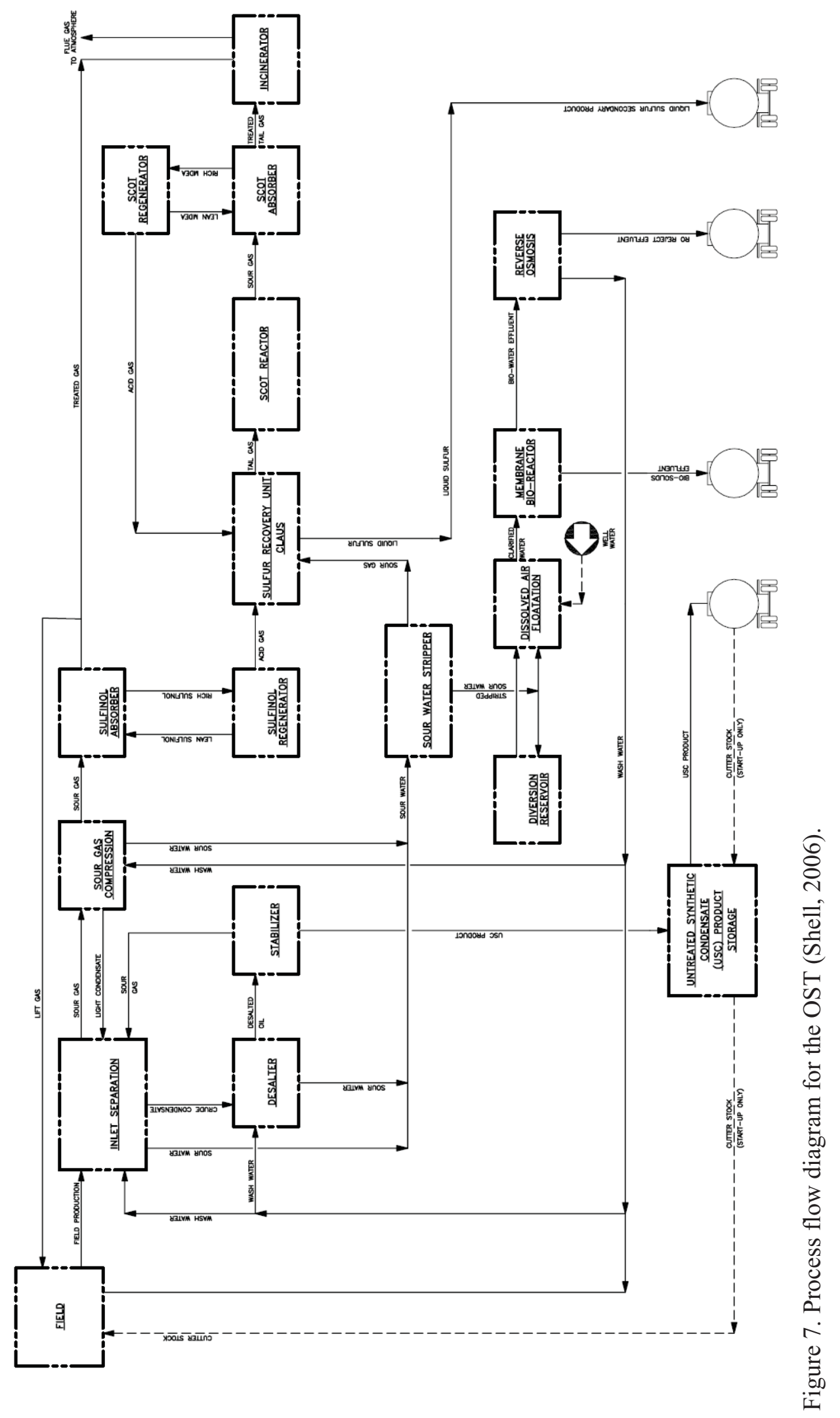




\subsection{References}

Bae, J. H. "Some effects of pressure on oil-shale retorting." Soc. Pet. Eng. J. 1969, (September), 287292.

Bartis, James T.; et al., "Oil Shale Development in the United States. Prospects and Policy Issues", Prepared for the National Energy Technology Laboratory of the United States Department of Energy. The RAND Corporation. 2005. ISBN 978-0-8330-3848-7.

Berchenko, I.; et al., In situ thermal processing of an oil shale formation using a pattern of heat sources. U.S. Patent 6991032 B2, January 31, 2006.

Birger, Jon (2007-11-01). “Oil shale may finally have its moment.” Fortune, November 1, 2007.

Burnham, A. K. "Chemical kinetics and oil shale process design"; Report UCRL-JC-114129; Lawrence Livermore National Laboratory, Livermore, CA, July 18-31, 1993.

Burnham, A. K.; McConaghy, J. R. "Comparison of the acceptability of various oil shale processes"; Report UCRLCONF- 226717; Lawrence Livermore National Laboratory: Livermore, CA, 2006.

Burnham, A. K.; Singleton,M.F. "High-Pressure Pyrolysis of Green River Oil Shale. In Geochemistry and Chemistry of Oil Shales"; Miknis, F. P., McKay, J. F., Eds.; ACS Symposium Series 230; American Chemical Society: Washington, DC, 1983.

Deeg, 2008, "Shell's Freeze Wall Test," 28th Oil Shale Symposium. Golden, Colorado, Colorado School of Mines.

Farkas, Tamas (2008). The Investor's Guide to the Energy Revolution. Lulu.com. pp. 85. ISBN 9781409202851 .

Hendrickson, T. A. Synthetic Fuels Data Handbook; Cameron Engineers, Inc.: Denver, CO, 1975.

Lee, Sunggyu; Speight, James G.; Loyalka, Sudarshan K. (2007). Handbook of Alternative Fuel Technologies. CRC Press. pp. 290. ISBN 9780824740696.

Mckinzie, B., H. Vinegar and M. Day, 2008, "Successful Test of a Frozen Ground Barrier to Flow," 28th Oil Shale Symposium. Golden, Colorado, Colorado School of Mines.

NPOSR, 2007, Secure Fuels from Domestic Resources: The Continuing Evolution of America's Oil Shale and Tar Sands Industries. United States Department of Energy, Office of Naval Petroleum and Oil Shale Reserves, June 2007. pp. 1-68.

Sanger, F. J.; Sayles, F. H. "Thermal and rheological computations for artificially frozen ground construction," Eng. Geol. 1979, 13, 311-377.

Savage, J.S., Oil Tech, Inc., Testimony before the Hearing on The Vast North American Resource Potential of Oil Shale, Oil Sands, and Heavy Oils - Part 1, House Subcommittee on Energy and Mineral Resources, June 23, 2005.

Shell, 2006, "Plan of Operations, Oil Shale Test Project, Oil Shale Research and Development Project," Shell Frontier Oil and Gas Inc., Prepared for: Bureau of Land Management, February 15, 2006.

Shell, 2010a, "ICP Timeline, Technology - In situ Conversion Process," http://www.shell.us/home/content/usa/aboutshell/shell_businesses/upstream/locations_projects/onsho $\mathrm{re} / \mathrm{mahogany} / \mathrm{mrp}$ technology.html

Shell, 2010b, "Technology - In situ Conversion Process,"

http://www.shell.us/home/content/usa/aboutshell/shell_businesses/upstream/locations_projects/onsho re/mahogany/mrp_technology.html 
Speight, James G. (2008). Synthetic Fuels Handbook: Properties, Process, and Performance. McGrawHill Professional. pp. 186. ISBN 9780071490238.

Spencer Reiss (2005-12-13), "Tapping the Rock Field". WIRED. http://www.wired.com/wired/archive/13.12/oilshale.html. Retrieved 2009-03-14.

Vinegar H., (2006), “Shell's In situ Conversion Process," National Academy of Sciences, 11 October 2006

Wong, S-W., T. Bai and S. Ekbote, 2007) "Geomechanics of Oil Shale In-situ Conversion Process," 27th Oil Shale Symposium. Golden, Colorado, Colorado School of Mines. 